\title{
Dexmedetomidine versus Lidocaineversus Ketamine to Alleviate Propofol Injection Pain: A Prospective Randomized Double Blind Study
}

\author{
Ranjini BN ${ }^{1}$, Vijay Siddhartha B $S^{2}$ \\ ${ }^{1}$ Senior Resident, Department of Anaesthesia, Subbaiah Institute of Medical sciences, Shivamogga, Karnataka, ${ }^{2}$ Assistant Professor, Department of \\ Anaesthesia, East point College of Medical sciences and research centre, Bangalore, Karnataka.
}

\section{Abstract}

Background: Ketamine (a phencyclidine derivative) has been recognized as a potent analgesic and local anesthetic properties but few studies have also been conducted to evaluate the utility of ketamine in reducing propofolinjection pain. Exact mechanism of analgesia effect is not clear. Subjects and Methods: 50 adult patients, in each group [group D, group L and group K] satisfying the inclusion criteria. The sample size is calculated based on previous studies as well as approximate availability of number of cases in the above mentioned duration satisfying inclusion and exclusion criteria in our college. Size of patients in each group is arrived at with $90 \%$ power at an alpha value of 0.05 to detect a $25 \%$ difference in severity of pain between the three groups. Results: There was a statistically significant difference in MAP and HR between the study groups. This may be attributed to the activation of the sympathetic nervous system by ketamine. Conclusion: As a consequence, BP is increased, which may attenuate the hypotensive effect of the propofol injection in our study.

Keywords: Dexmedetomidine, Lidocaine, Ketamine.

Corresponding Author: Dr. Vijay Siddhartha B S, Assistant Professor, Department of Anaesthesia, East point College of Medical sciences and research centre, Bangalore, Karnataka.

Received: December 2019

Accepted: December 2019

\section{Introduction}

Propofol[ Diprivan, 2,6- di- isopropylphenol is the drug of choice for induction of anesthesia in millions of patients every year because of its rapid onset and short duration of action, easy titration, favourable profile for side effects, and its smooth induction and rapid recovery characteristics. Propofol injection pain [PIP], a well-known clinical phenomenon has an incidence ranging from $28 \%$ to $90 \%$ in adults. ${ }^{[1]}$

Among the interventions, intravenous [IV] lidocaine, a timetested local anesthetic of the amide group is the commonly used drug but it has a failure rate of $13 \%-32 \%$.

On the other hand, dexmedetomidine is a potent, highly specific and selective $\alpha-2$ adrenoceptor agonist with potent sedative, analgesic and sympatholytic effects. Acts by inhibiting the release of substance $\mathrm{P}$ from the dorsal horn of the spinal cord. ${ }^{[2]}$

Another drug used to decrease propofol injection pain is ketamine. Ketamine (a phencyclidine derivative) has been recognized as a potent analgesic and local anesthetic properties but few studies have also been conducted to evaluate the utility of ketamine in reducing propofolinjection pain. Exact mechanism of analgesia effect is not clear. ${ }^{[3]}$

However, it was suggested that the reduction in propofol injection pain was the result of a peripheral action which attenuated the afferent pain pathways. Ketamine as a NMDA receptor antagonist may activate these receptors either in the vascular endothelium or in the central nervous system. ${ }^{[4]}$

But no study has compared the efficacy between these three drugs. The aim of this study is to compare the effects of prior administration of dexmedetomidine VS lidocaine VS ketamine.

\section{Subjects and Methods}

After approval from the ethical committee and written informed consent from the patients, 150 patients were selected according to the following criteria:

\section{Inclusion criteria}

- In a good health ( ASA I and II )

- Patients aged 18-50 years belonging to either sex

- Undergoing elective surgery under general anesthesia

\section{Exclusion criteria}

- Patient unwilling to participate in the study

- Difficulty in communication

- History of adverse effects with propofol and study drugs

- Those who required rapid sequence induction 
- Those having difficulty in venous access

- Pregnant females

- Those who received any kind of analgesic or sedative in the 24 hours prior to surgery

- History of drug abuse

- Taking regular analgesics

- Suffering from acute / chronic pain syndromes

- Psychiatric disease, seizures

- Uncontrolled hypertension

- Renal/ hepatic impairment

Study subjects: Patients hospitalized for elective surgeries. Study design:Randomized clinical trial

Sample size: 50 adult patients, in each group [group D, group $\mathrm{L}$ and group $\mathrm{K}$ ] satisfying the inclusion criteria.The sample size is calculated based on previous studies as well as approximate availability of number of cases in the above mentioned duration satisfying inclusion and exclusion criteria in our college. Size of patients in each group is arrived at with $90 \%$ power at an alpha value of 0.05 to detect a $25 \%$ difference in severity of pain between the three groups.

Group D [Dexmedetomidine] - subject will receive 0.25 $\mathrm{mcg} / \mathrm{kg}$ of Dexmedetomidine.

Group L [Lignocaine] - subject will receive $0.5 \mathrm{mg} / \mathrm{kg}$ of Lignocaine.

Group K [Ketamine] - subject will receive $0.5 \mathrm{mg} / \mathrm{kg}$ of Ketamine.

All patients will be evaluated a day prior to surgery and they will be explained about the procedure in detail in the pre-op visit prior to obtain written informed consent.

Patient will be kept Nil per oral as per standard guidelines.

In the operation room, an $18 \mathrm{G}$ cannula will be inserted in the dorsum of hand

In the operation room patients will be monitored with standard anesthetic monitoring techniques like electrocardiogram [ECG] device, pulse oximeter and automated noninvasive arterial blood pressure monitor.

All the patients will be premedicated with injections of $50 \mathrm{mg}$ of Ranitidine and $10 \mathrm{mcg} / \mathrm{kg}$ of intravenous [IV] glycopyrrolate at least 30 minutes before the surgery.

Patients will be randomly assigned into 3 groups to receive IV $0.25 \mu \mathrm{g} / \mathrm{kg}$ dexmedetomidine or $0.5 \mathrm{mg} / \mathrm{kg}$ of ketamine or $0.5 \mathrm{mg} / \mathrm{kg}$ of lidocaine. A randomization list will be prepared by a random number function on a computer spread sheet.

The patient received the premedicant drug according to whichever group he/she belongs to.

The premedicant will be administered by a fellow anesthesiologist colleague.

For the purpose of creating double blind conditions neither the patient nor the anesthesiologist (researcher) will know the identity of premedicants.

A rubber tourniquet will be used to perform 1 minute of venous occlusion before administration of the study drug with the aim to keep the drug within the vein.

Through the cannula, the study drug diluted to $5 \mathrm{cc}$ with normal saline will be injected over 5 seconds. The occlusion will be released after 1 minute and $25 \%$ of the induction dose of propofol $[2 \mathrm{mg} / \mathrm{kg}]$ will be administered over 10 seconds by a syringe.

During Propofol injection, patients was asked standard questions by a blind investigator regarding the comfort of the injection and will be continuously observed for vocal response, facial grimacing, arm withdrawal, or tears suggesting severe pain. Pain will be graded using the four point scale of McCririck et al.

Thereafter, induction of anesthesia will be continued with the remainder of the calculated dose of propofol. Scoline $1.5 \mathrm{mg} / \mathrm{kg}$ will be administered for muscle relaxation and to facilitate tracheal intubation will be performed using appropriate sized endotracheal tube, and anesthesia will be maintained with isoflurane, injection of atracurium/ vecuronium, nitrous oxide $(\mathrm{N} 2 \mathrm{O}) 66 \%$ in oxygen $(\mathrm{O} 2)$, with controlled ventilation and perioperative analgesia will be taken care with

injectionparacetamol $15 \mathrm{mg} / \mathrm{kg}$ 6th hourly to a maximum dose of $4000 \mathrm{mg}$. Reversal of muscle relaxation will be done using injection Neostigmine $0.05 \mathrm{mg} / \mathrm{kg}$ with injection Glycopyrrolate $10 \mathrm{mcg} / \mathrm{kg}$

Incidence and intensity of pain (as assessed by mean pain scores) will be determined in all three study groups.

Within 24 hours after the operation, the injection site will be checked for pain, edema and wheal flare response. The data collected will be tabulated and analyzed.

\section{Results}

Table 1: Pain
\begin{tabular}{|l|l|l|l|}
\hline Pain & Group L & Group D & Group K \\
\hline No pain & $44(88 \%)$ & $26(52 \%)$ & $40(80 \%)$ \\
\hline Mild pain & $03(06 \% 0$ & $08(216 \%)$ & $06(12 \%)$ \\
\hline Moderate pain & $02(04 \%)$ & $10(20 \%)$ & $03(06 \%)$ \\
\hline Severe pain & $01(02 \%)$ & $06(12 \%)$ & $01(02 \%)$ \\
\hline Total & $50(100 \%)$ & $50(100 \%)$ & $50(100 \%)$ \\
\hline
\end{tabular} P value $=0.001$

Table 2: Demographic data

\begin{tabular}{|l|l|l|l|}
\hline Demographic data & Group L & Group D & Group K \\
\hline Age(yrs) & $32.3+/-4.2$ & $31.2+/-4.6$ & $32.1+/-4.8$ \\
\hline Duration of surgery (min) & $63.2+/-4.8$ & $61.2+/-5.2$ & $62.3+/-5.1$ \\
\hline Sex (male/female) & $28 / 22$ & $27 / 23$ & $24 / 26$ \\
\hline ASA (I/II) & $30 / 20$ & $24 / 26$ & $26 / 24$ \\
\hline Total & 50 & 50 & 50 \\
\hline
\end{tabular}

\begin{tabular}{|c|c|c|c|}
\hline & Groun I & Groun D & Groun $K$ \\
\hline Before induction & $\begin{array}{l}101.1+/- \\
12.6\end{array}$ & $97.5+/-11.3$ & $99.2+/-13.4$ \\
\hline $\begin{array}{l}\text { At the time of } \\
\text { administration of study } \\
\text { drug }\end{array}$ & $98.6+/-10.6$ & $97.2+/-13.0$ & $96.4+/-11.4$ \\
\hline $\begin{array}{l}\text { At the time of } \\
\text { administration of } 25 \% \text { of } \\
\text { calculated dose of } \\
\text { propofol }\end{array}$ & $97.2+/-8.2$ & $98.1+/-9.6$ & $\begin{array}{l}102.4+/- \\
10.4\end{array}$ \\
\hline $\begin{array}{l}\text { At the time of } \\
\text { administration of rest of } \\
\text { the propofol }\end{array}$ & $97.4+/-7.4$ & $88.4+/-10.2$ & $\begin{array}{l}101.2+/- \\
13.3\end{array}$ \\
\hline \multicolumn{4}{|l|}{ At Intubation } \\
\hline $0 \mathrm{~min}$ & $96.4+/-8.6$ & $88.3+/-8.4$ & $92.4+/-11.4$ \\
\hline $1 \min$ & $96.2+/-10.2$ & $81.2+/-9.2$ & $90.2+/-12.6$ \\
\hline $3 \min$ & $97.4+/-8.3$ & $98.6+/-10.4$ & $94.7+/-13.4$ \\
\hline
\end{tabular}


Table 4: Heart Rate in groups

\begin{tabular}{|l|l|l|l|}
\hline & Group L & Group D & Group K \\
\hline Before induction & $90.3+/-14.4$ & $86.1+/-15.4$ & $88.2+/-13.6$ \\
\hline $\begin{array}{l}\text { At the time of } \\
\text { administration of study } \\
\text { drug }\end{array}$ & $91.8+/-14.6$ & $88.4+/-12.6$ & $92.5+/-12.8$ \\
\hline $\begin{array}{l}\text { At the time of } \\
\text { administration of } 25 \% \text { of } \\
\text { calculated dose of } \\
\text { propofol }\end{array}$ & $96.5+/-12.6$ & $74.3+/-15.6$ & $\begin{array}{l}100.1+/- \\
14.6\end{array}$ \\
\hline $\begin{array}{l}\text { At the time of } \\
\text { administration of rest of } \\
\text { the propofol }\end{array}$ & $95.7+/-10.2$ & $72.5+/-14.2$ & $98.2+/-15.4$ \\
\hline At Intubation & & & \\
\hline 0 min & $96.6+/-11.4$ & $76.4+/-16.6$ & $96.2+/-17.2$ \\
\hline 1 min & $94.3+/-13.2$ & $78.1+/-13.2$ & $\begin{array}{l}102.9+/- \\
16.6\end{array}$ \\
\hline 3 min & $98.4+/-12.4$ & $79.5+/-12.6$ & $\begin{array}{l}101.6+/- \\
14.8\end{array}$ \\
\hline
\end{tabular}

\section{Discussion}

In this study, the primary aim was to compare lidocaine, dexmedetomidine, with ketamine infusion to decrease propofol pain.

The mechanism of the pain caused by propofol injection remains unclear. There are two suggested mechanisms for this pain: the first is direct irritation and the second is an indirect effect through the kinin cascade. Bradykinin produces local vasodilation, and it increases the permeability, which may increase the contact with free nerve endings.

The use of a tourniquet was considered as an important tool to study the peripheral action of the drug in the absence of its central action.

In this study the incidence of pain in lidocaine group was reported to be $12 \%, 48 \%$ in dexmedetomidine and $20 \%$ in ketamine group.

There was a statistically significant difference in MAP and HR between the study groups. This may be attributed to the activation of the sympathetic nervous system by ketamine. As a consequence, BP is increased, which may attenuate the hypotensive effect of the propofol injection in our study.

Thukral et $\mathrm{al}^{[1]}$ conducted a study and found that ketamine $0.5 \mathrm{mg} / \mathrm{kg}$ slow IV infusion immediately before the propofol injection appears to be more effective in reducing the incidence and severity of the PIP than Dexmedetomidine $0.5 \mathrm{mcg} / \mathrm{kg}$ infusion pre- treatment.

Elsayed et al ${ }^{[2]}$ conducted a study and found that pretreatment with ketamine $0.5 \mathrm{mg} / \mathrm{kg}$ was more effective than pretreatment with lidocaine $0.5 \mathrm{mg} / \mathrm{kg}$.

Singh et al conducted a study on 105 patients and found that pretreatment with $0.25 \mathrm{mcg} / \mathrm{kg}$ of Dexmedetomidine with venous occlusion for one minute is also as effective as IV Lidocaine $0.5 \mathrm{mcg} / \mathrm{kg}$ pretreatment in alleviating propofol injection pain when compared to placebo, even though lidocaine is better than dexmedetomidine.

Liang $\mathrm{He}$ et $\mathrm{al}^{3}$ in a study on 210 patients found that pretreatment with dexmedetomidine $1 \mathrm{mcg} / \mathrm{kg} 5 \mathrm{~min}$ prior to injection of long-chain triglyceride propofol is effective and safe in reducing the incidence and severity of pain due to propofol injection.

Alparslan et $\mathrm{al}^{[4]}$ conducted a study on 75 subjects and found that ketamine $10 \mathrm{mg}$ has similar effects with lidocaine $40 \mathrm{mg}$ in reducing propofol medium chain triglyceride/ long chain triglyceride, the new formation of propofol injection pain.

Hwang et $\mathrm{al}^{[5]}$ conducted a study on 130 patients and found that pretreatment with IV lidocaine $40 \mathrm{mg}$ plus ketamine $25 \mathrm{mg}$ with a rubber tourniquet on the forearm $1 \mathrm{~min}$ before the injection of microemulsionpropofol is more effective than lidocaine $40 \mathrm{mg}$ or ketamine $25 \mathrm{mg}$ alone in preventing pain from the injection of microemulsionpropofol.

Polat et $\mathrm{al}^{[6]}$ conducted a study on 250 patients and found that lidocaine $40 \mathrm{mg}$ was more effective than ketamine 100 $\mathrm{mcg} / \mathrm{kg}$ in reducing propofol injection pain.

Jalotaet $\mathrm{al}^{[7]}$ in a recent review and meta-analysis on 25260 adults concluded that one of the two most efficacious interventions to reduce pain on injection of propofol was pretreatment using lidocaine in conjunction with venous occlusion.

Zepeda et $\mathrm{al}^{[8]}$ in a study on 500 patients found that administration of ketamine $100 \mathrm{mcg} / \mathrm{kg}$ immediately before propofol injection is a safe and effective method in preventing propofol injection pain.

Iwata et $\mathrm{al}^{[9]}$ conducted a study on 45 patients scheduled for elective lung surgeries and concluded that $1 \mathrm{mg} / \mathrm{kg}$ of ketamine completely eliminated pain associated with propofol injection without affecting hemodynamics during induction of anesthesia.

Koo et $\mathrm{al}^{[10]}$ conducted a study on 240 patients and concluded that administration of ketamine $100 \mathrm{mcg} / \mathrm{kg}$ immediately before propofol injection provided the optimal dose and timing to reduce propofol induced pain on injection.

Sarkilar et $\mathrm{al}^{[11]}$ in a study on 250 adults found that Dexmedetomidine infusions in pre-anesthetic sedative doses of $0.5 \mathrm{mcg} / \mathrm{kg}$ and $1 \mathrm{mcg} / \mathrm{kg}$ decrease the incidence of propofol injection pain compared to placebo. ${ }^{[12]}$

\section{Conclusion}

We observed that there was a significant difference between pretreatment with dexmedetomidine, ketamine and lignocaine in attenuating the pain caused by propofol.

Pretreatment with lignocaine was the most effective with least significant hemodynamic changes and pretreatment with dexmedetomidine was the least effective in attenuating propofol infusion pain.

Incidences of complications were not significant between all the study groups.

\section{References}

1. SeemaThukral, Priyanka Gupta, ArchanaLakra, Mayank Gupta Dexmedetomidine versus ketamine infusion to alleviate propofol injection pain: A prospective rendominized and double Blind study; Indian J Anaesth 2015; 59: 488-92

2. AymanA Elsayed MD ${ }^{1}$, Ayman A Rayan ${ }^{2}$ A comparative study between a small dose of ketamine, lidocaine $1 \%$, and acetominophen infusion to decrease propofol injection pain. ASJA. Year: 2015 | Volume : 8 | Issue : 3 | Page : 437-442

3. Lee JH, Jung SY, Kim M H, Cho K. The effect of dexmedetomidine on propofol injection pain. Korean J Anesthesiol 2014:67suppl:S 30-1

4. Mustafa Muhlis Alparslan1, Koray Ak1,2, Emine Dinçer1, Cevdet Düger3 Placebo-controlled comparison of using lidocaine or ketamine to reduce the pain during injection of propofol containing a mixture of medium-chain triglyceride/long-chain triglyceride Basic ClinSci 2013; 2: $116-122$

5. Hwang J, Park HP, Lim Y J, Do sh, Lee SC, Jeon YT. Preventing pain 
on injection of propofol: a comparison between peripheral ketamine pretreatment and ketamine added to propofolAnesth Intensive care 2009;37:584-7

6. Polat $\mathrm{R}^{1}$, Aktay M, Ozlü O.The effects of remifentanil, lidocaine, metoclopramide, or ketamine pretreatment on propofol injection pain.Middle East J Anaesthesiol. 2012 Jun;21(5):673-7.

7. Jalota L, Kalira V, George E, Shiyy, Hornuas C, Radke O et al . Prevention of pain on injection of propofol. Systematic review and metaanalysis. BMJ 2011:342 D 1110

8. Zepeda, E. A., Veline, R. J., and Crook, R. J. (2017). Rapid associative learning and stable long-term memory in the squid Euprymnascolopes. Biol. Bull. 232, 212-218. doi: $10.1086 / 693461$

9. Iwata $\mathbf{M}^{1}$, Inoue $\mathrm{S}$, Kawaguchi $\mathbf{M}$, Kimura $\mathrm{T}$, Tojo $\mathrm{T}$, Taniguchi
S, Furuya H. Ketamine eliminates propofol pain but does not affect hemodynamics during induction with double-lumen tubes.J Anesth. 2010 Feb;24(1):31-7.

10. KoosW,Cho SJ, Kim YK, Ham K D ,Hwang JH Small dose ketamine reduces the pain of propofol injection. Aneasthesilogy 2000; 103: 1444-7

11. Sarkilar G, Kara I, Duman A, Okesli S. Effect of dexmedetomidine on pain caused by injection of propofol Nobel Med.2012;8:83[8]

12. Singh, H.S. \& Singh, L.D. \& Singh, N.R. \& Singh, T.H. \&Thokchom, R.S. \&Monohar, P.S.. (2015). Effects of dexmedetomidine and lidocaine in alleviating propofol injection pain: A randomized controlled trial. JMS - Journal of Medical Society. 29. 31-34. $10.4103 / 0972-4958.158929$.

Copyright: (c) the author(s), publisher. Academia Anesthesiologica Internationalis an Official Publication of "Society for Health Care \& Research Development". It is an open-access article distributed under the terms of the Creative Commons Attribution Non-Commercial License, which permits unrestricted non-commercial use, distribution, and reproduction in any medium, provided the original work is properly cited.

How to cite this article: Ranjini BN, Vijay Siddhartha B S. Dexmedetomidine versus Lidocaineversus Ketamine to Alleviate Propofol Injection Pain: A Prospective Randomized Double Blind Study. Acad. Anesthesiol. Int. 2019;4(2):353-56.

DOI: dx.doi.org/10.21276/aan.2019.4.2.80

Source of Support: Nil, Conflict of Interest: None declared. 